\title{
Is an IOC Still Necessary during Laparoscopic Cholecystectomy?
}

\author{
$\mathrm{Li} \mathrm{J}{ }^{* 1}$, Puhalla $\mathrm{H}^{1}$, Chu FC ${ }^{2}$ and $\mathrm{Li} \mathrm{HK}^{3}$ \\ ${ }^{1}$ Griffith University, School of Medicine, Gold Coast, Australia \\ ${ }^{2}$ St George Hospital, Kogarah, Australia \\ ${ }^{3} \mathrm{St}$ Vincent private hospital, Brisbane, Australia
}

*Corresponding author: Li J, Griffith University, School of Medicine, Gold Coast, Australia, Tel: +61 413199

059, E-mail: Johnhinkongli@gmail.com

\author{
Citation: Li J, Puhalla H, Chu FC, Li HK (2017) Is an Ioc Still Necessary During Laparoscopic \\ Cholecystectomy? J Surg Oper Care 2(1): 102. doi: 10.15744/2455-7617.2.102
}

Received Date: August 07, 2017 Accepted Date: October 03, 2017 Published Date: October 05, 2017

\begin{abstract}
Introduction: Routine intraoperative cholangiogram (IOC) during laparoscopic cholecystectomy (LC) helps to confirm biliary anatomy and reduce bile leaks. It also allows identification of common bile duct stones intraoperatively which in selected patients can be cleared transcystically in the same procedure which is much less morbid than through post-operative endoscopic retrograde cholangiopancreatography (ERCP). Despite this, some surgeons only selectively perform IOC or forgot it all together.

Aim: This study aims to assess the safety and feasibility of performing IOCs routinely and how this can facility transcystic CBD stone management.

Methods: We conducted a study based on a prospectively collected database of all patients in the Gold Coast Health District and St George Hospital who underwent LC between June 2010 and December 2012. IOC was attempted in all cases. Demographic data collected included age, sex, and type of admission. Outcome measured included the completion of IOC, postoperative ERCP and bile duct leaks. Categorical variables were compared using the chi-squared analysis using STATA version 13.1. Results were considered statistically significant at $\mathrm{p}<$ 0.05 .

Results: IOC was completed in 1408 (90\%) of the 1564 LCs included in the study. Transcystic CBDE was attempted in 127 cases and was successfully completed in 97 cases giving a clearance rate of $76 \%$. The number of patients needed to treat (IOC) in order to prevent an ERCP was 18.5. There was also no statistically significant difference when comparing the number of bile leaks detected in those who have transcystic CBDE compared those all patients who had an LC [3(2.36\%) vs 18(1.25\%), $\left.\chi^{2}=1.08, p=0.30\right]$.
\end{abstract}

Conclusions: Routine Cholangiogram has a place in LC for improved safety and stone recognition. It also facilitates the learning and maintenance of skills for transcystic clearance of CBD stones which is a safe alternative to the highly morbid ERCP.

Keywords: Intraoperative cholangiogram (IOC); Common bile duct (CBD) stones; Transcystic; Laparoscopic Cholecystectomy

\section{Introduction}

The use of intraoperative cholangiogram (IOC) has significantly decreased since the introduction of the laparoscopic approach to cholecystectomies [1]. Despite the unchanged fact that in 10\% of patients undergoing laparoscopic cholecystectomy (LC) Common bile duct (CBD) stones are encountered [2-4]. The IOC helps to confirm biliary anatomy and identify bile duct injuries intraoperatively and therefore facilitates early management [5-7]. Regarding CBD stones, despite authors advocating pre-operative algorithms using liver function test and ultrasonography to predict them, approximately 30-50\% of CBD stones present themselves in an unsuspicious manner. In addition, when ERCP is performed pre-operatively for suspected CBD stones only $20-60 \%$ of cases a positive for stones, subjecting patients unnecessarily to the complications of ERCP including pancreatitis, haemorrhage and duodenal perforation $[2,3,8,9]$.

IOC allows stone recognition intraoperatively and if identified simultaneous Laparoscopic Common Bile Duct Exploration (LCBDE) can be performed to clear the CBD stones. There is increasing evidence suggesting benefits of a one-step procedure (including LC and LCBDE) over a delayed duct clearance with ERCP $[4,10,12]$. LCBDE can be performed through the same incision as the IOC, transcystically or through choledochotomy, a separate incision in the CBD. While laparoscopic choledochotomy is more technically demanding and associated with significant morbidity, transcystic extraction can be performed with skills developed with routine IOC with minimal increase in morbidity and hospital stay [4,13]. Despite this, some surgeons only selectively perform 
IOCs or forgo it all together [14]. This study aims to assess the safety and feasibility of performing IOCs routinely and how this can facility transcystic CBD stone management.

\section{Methods}

\section{Patients}

We conducted a study based on a prospectively collected database of all patients in the Gold Coast Health District and St George Hospital who underwent LC between June 2010 and December 2012. In cases of missing data, retrospective chart analysis was done. Our approach, technique and selection criteria for transcytotic (TC) and choledochotomy (CD) explorations have been previously published [1].

Patients who had pre-operative ERCP, conversion to open procedure, combinational surgeries involving other organs outside that of the biliary tract and those that did not have complete data were excluded in the study.

\section{Data Collection}

Collection of data was initiated after December 2012. Charts including patient's operation and ERCP reports, discharge summaries were reviewed at a minimum of three months post operation.

IOC was attempted in all cases. Cases, where IOC was aborted due to inability to cannulate the cystic duct or deemed unsafe, were defined as 'Incomplete-IOC'.

If bile was seen at the end of the operation after washout and required the insertion of a drain, this was considered a 'bile duct leak' from the cystic duct. A 'major bile duct leak' is defined by those that did not self-resolve within 5 days leading to further investigation to look for a CBD injury or requiring or further intervention.

ERCP was performed in post-operative patients with persistent abdominal pain, deranged liver function tests and radiological evidence of retained stones or if a stone was identified on IOC and was unable to be extracted with LCBDE. ERCP was performed within the same hospital admission.

'Stone clearance' was deemed unsuccessful if the patient required post-op ERCP.

\section{Statistical analysis}

A series of binary logistic regressions were conducted using Stata Version 13.1 controlling for demographic variables to answer key research questions (Statacorp, 2013). Results were considered statistically significant at $p<0.05$. We also conducted missing variable analysis and there were less than $5 \%$ of data 97 missing in the descriptive of age and gender, no other data was missing from the 98-data set. It was determined that the data were missing at random.

\section{Results}

Between June 2010 and December 2012 there were a total of 1564 patients that fit the selection criteria. IOCs were completed in 1408 (90\%) cases. Table 1 shows the demographic data effecting the successful conduction of IOC.

\begin{tabular}{|c|c|c|c|c|}
\hline & IOC & Incomplete IOC & OR & p \\
\hline $\mathbf{n}(\%)$ & $1408(90 \%)$ & $156(10 \%)$ & & \\
\hline $\begin{array}{c}\text { Female } \\
\text { Male }\end{array}$ & $\begin{array}{c}970(70 \%) \\
407\end{array}$ & $\begin{array}{c}92(60 \%) \\
59\end{array}$ & 1.38 & 0.08 \\
\hline Age, M (SD) & $49.20(17.07)$ & $52.21(17.76)$ & .99 & 0.18 \\
\hline $\begin{array}{c}\text { Elective } \\
\text { Emergency }\end{array}$ & $\begin{array}{c}943(67 \%) \\
465\end{array}$ & $\begin{array}{c}72(46 \%) \\
84\end{array}$ & 2.30 & $<0.05$ \\
\hline
\end{tabular}

Table 1: Demographic data

We also conducted missing variable analysis and there were less than $5 \%$ of data missing in the descriptive of age and gender, no other data was missing from the dataset. It was determined that the data were missing at random.

When these descriptive variables were considered in conjunction in a logistic regression, it was found that age and gender were not significant predictors of IOC completion. IOC was more likely to be completed on elective LC when compared to emergency LCs [93\% vs $85 \%$, OR $2.3, p<0.05]$.

\section{Common bile duct stones}

We identified 169 of the 191 stones with IOC (88\%). The sensitivity, specificity, negative predictive value, and positive predictive value were $88.5 \%, 100 \%, 98.4 \%$ and $100 \%$ respectively.

Transcystic CBDE was attempted in 127 cases and was successfully completed in 97 cases giving a clearance rate of $76 \%$. The 
number of patients needed to treat (IOC) in order to prevent an ERCP was 18.5. The other 42 cases were not eligible for transcystic and were cleared via colectomy. Post-operative ERCP detected an additional 22 CBDS that were not detected with IOC. value were $88.5 \%, 100 \%, 98.4 \%$ and $100 \%$ respectively.

\section{Bile leaks}

There was no statistically significant difference comparing the number of bile leaks detected in those who had a complete IOC compared to those who had an incomplete IOC $\left[17(1.21 \%)\right.$ vs $\left.4(2.56 \%), \chi^{2}=1.95, p=0.16\right]$. There was also no statistically significant difference when comparing the number of bile leaks detected in those who have transcystic CBDE compared those all patients who had an LC $\left[3(2.36 \%)\right.$ vs $\left.18(1.25 \%), \chi^{2}=1.08, p=0.30\right]$.

\section{Discussion}

As routine Cholangiographers, we completed IOCs in 90\% of LCs. This is similar to previous studies' completion rates of 9095\% [5,14]. Age and sex did not affect the ability to conduct IOC, however, there was a statistical difference in between type of admission. The decreased rate of IOC completed in the emergency group may be accounted for by the more technically demanding dissection of the acutely inflamed gallbladder as highlighted by a prospective study by Dominguez et al [15].

The learning curve of performing IOCs has been documented at 46 with an additional operative time of 10 to 16 minutes per IOC $[6,14,16]$. To achieve this number, surgeons and trainees would benefit from routinely performing IOC as this will help to learn and to maintain skills especially for more difficult cases $[6,14]$.

While one of the main aims of the IOC is to improve identification of the biliary anatomy and hence decrease significant bile duct injuries, there may be fear that routine IOC may increase rates of bile duct leaks. There were no major bile leaks or bile duct injuries identified in either the IOC or the incomplete IOC groups. There was also no statistically significance difference between the two groups in terms of bile leaks $\left[17(1.21 \%)\right.$ vs $\left.4(2.56 \%), \chi^{2}=1.95, p=.16\right]$. While a recent meta-analysis conducted by Slim et al showed variation between positive protective effect and no effect of IOCs on biliary leaks, the two biggest studies reviewed suggest that IOCs could decrease major biliary injuries [7].

The second advantage of routine IOCs is recognition of stones in the CBD intraoperatively. We identified $88 \%$ of CBD stones and proceed to therapeutic measures in a single procedure. The transcystic CDBE clearance rate of $76 \%$ found in this study is comparable to previously reported rates $80.4-100 \%$ [4]. Transcystic CBDE was safe to performed with no increased rate of bile duct leaks when compared to LC $\left[3(2.36 \%)\right.$ vs $\left.18(1.25 \%), \chi^{2}=1.08, p=0.30\right]$. Through this route, one ERCP was prevented for every 18.5 IOCs we performed.

\section{Limitations}

Our data focused mainly on CBD stone recognition and clearance as well as the presence of bile leaks. Further studies could focus on other predictors of safety including additional operative time, blood loss and length of stay.

\section{Conclusion}

Routine Cholangiogram has a place in LC for improved safety and stone recognition. It also facilitates the learning and maintenance of skills for transcystic clearance of CBD stones which is a safe alternative to the highly morbid ERCP.

\section{References}

1. Puhalla, H, Flint N, O'rourke N (2015) Surgery for common bile duct stones--a lost surgical skill; still worthwhile in the minimally invasive century? Langenbecks Arch Surg 400: 119-127.

2. O’Neill CJ, Gillies DM, Gani JS (2008) Choledocholithiasis: overdiagnosed endoscopically and undertreated laparoscopically. ANZ J Surg 78: 487-91.

3. Santo MA, Domene CE, Riccioppo D, Barreira L, Takeda FR, et al. (2012) Common bile duct stones: analysis of the video-laparoscopic surgical treatment. Arq Gastroenterol 49: 41-51.

4. Reinders JS, Gouma DJ, Ubbink DT, et al. (2014) Transcystic or transductal stone extraction during single-stage treatment of choledochocystolithiasis: a systematic review. World J Surg 38: 2403-11.

5. Alvarez FA, de Santibañes M, Palavecino M, Sánchez Clariá R, Mazza O, et al. (2014) Impact of routine intraoperative cholangiography during laparoscopic cholecystectomy on bile duct injury. Br J Surg 101: 677-84.

6. Detry O, De Roover A, Detroz B (2003) The role of intraoperative cholangiography in detecting and preventing bile duct injury during laparoscopic cholecystectomy. Acta Chir Belg 103: 161-2.

7. Slim K, Martin G (2013) Does routine intra-operative cholangiography reduce the risk of biliary injury during laparoscopic cholecystectomy? An evidencebased approach. J Vasc Surg 150: 321-4.

8. Nathanson LK, O’Rourke NA, Martin IJ, Fielding GA, Cowen AE, et al. (2005) Postoperative ERCP versus laparoscopic choledochotomy for clearance of selected bile duct calculi: a randomized trial. Ann Surg 242: 188-92.

9. Silva AA, Camara CA, Martins A, Teles CJ, Terra JA, et al. (2013) Intraoperative cholangiography during elective laparoscopic cholecystectomy: selective or routine use? Acta Cir Bras 28: 740-3.

10. Tranter SE, Thompson M (2002) Comparison of endoscopic sphincterotomy and laparoscopic exploration of the common bile duct. Br J Surg 89: 1495-504. 
11. Freeman M (1998) Complications of endoscopic sphincterotomy. Endoscopy 30: A216-20.

12. Liu JG, Wang YJ, Shu GM, Lou C, Zhang J, et al. (2014) Laparoscopic versus endoscopic management of choledocholithiasis in patients undergoing laparoscopic cholecystectomy: a meta-analysis. J Laparoendosc Adv Surg Tech A 24:287-94.

13. Zhu JG, Han W, Zhang ZT, Guo W, Liu W, et al. (2014) Short-term outcomes of laparoscopic transcystic common bile duct exploration with discharge less than 24 hours. J Laparoendosc Adv Surg Tech A 24: 302-5.

14. Pesce A, Portale TR, Minutolo V, Scilletta R, Li Destri G, et al (2012) Bile duct injury d1uring laparoscopic cholecystectomy without intraoperative cholangiography: A retrospective study on 1,100 selected patients. Digestive Surgery 29: 310-4.

15. Molloy M, Archer SB, Hasselgren PO, Dalton BJ, Bower RH (1999) Cholangiogram during laparoscopic cholecystectomy cumulative sum analysis of an institutional learning curve. J Gastrointest Surg 3: 185-8.

16. Dominguez EP, Giammar D, Baumert J (2006) A prospective study of bile leaks after laparoscopic cholecystectomy for acute cholecystitis. Am Surg 72: 265-8.

17. Ding G, Cai W, Qin M (2015) Is intraoperative cholangiography necessary during laparoscopic cholecystectomy for cholelithiasis? World J Gastroenterol 21: 2147-51.

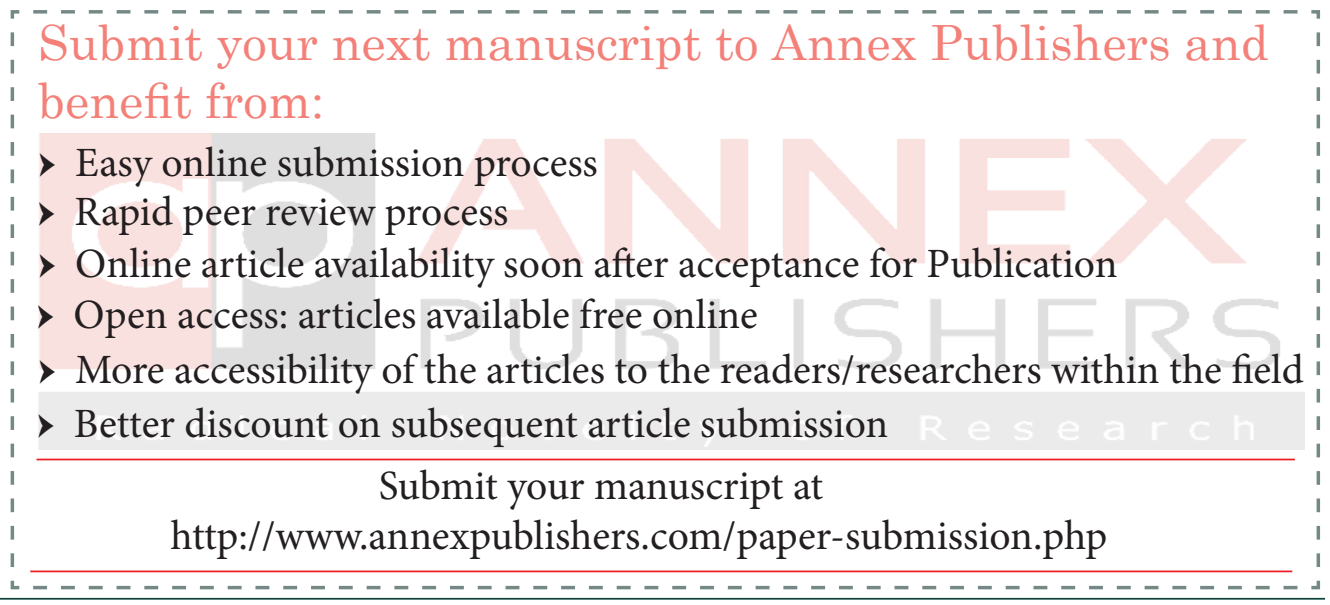

